B. А. Рубан, В. В. Помыткин. Интеграционная модель бизнеса в сфере воздушного транспорта в рамках проводимой государственной политики

УДК 336.73

DOI 10.18101/2304-4446-2019-1-33-39

\title{
ИНТЕГРАЦИОННАЯ МОДЕЛЬ БИЗНЕСА В СФЕРЕ ВОЗДУШНОГО ТРАНСПОРТА В РАМКАХ ПРОВОДИМОЙ ГОСУДАРСТВЕННОЙ ПОЛИТИКИ
}

\section{(C) Рубан Владимир Алексеевич}

доктор экономических наук, профессор,

Сибирский государственный университет путей сообщения

Россия, 630049, г. Новосибирск, ул. Дуси Ковальчук, 191

E-mail: gmu@sgups.stu.ru

\author{
(С) Помыткин Владимир Владимирович \\ аспирант, \\ Сибирский государственный университет путей сообщения \\ Россия, 630049, г. Новосибирск, ул. Дуси Ковальчук, 191 \\ E-mail:gmu@sgups.stu.ru
}

Исследование практических аспектов функционирования воздушного транспорта в России и проводимой в этой сфере государственной политики показало необходимость совершенствования данных процессов. В статье обосновано, что одним из перспективных направлений улучшения государственного регулирования экономической деятельности является интеграция бизнес-структур при реализации внутрирегиональных, межрегиональных и межстрановых авиаперевозок, для чего предложена интеграционная модель бизнеса в сфере воздушного транспорта в рамках проводимой государственной политики. Предложенная модель отражает связь между экономикой, спросом на воздушные перевозки и предложением авиакомпаний, что позволяет учитывать интересы всех субъектов взаимодействия. Разработан методический подход к формированию стратегических векторов развития воздушного транспорта, направленных на построение системы транспортного обслуживания, основой которой является экономическая интеграция бизнеса в сфере воздушного транспорта.

Ключевые слова: экономическая интеграция; государственное регулирование; авиаперевозки; воздушный транспорт.

\section{Для цитирования:}

Рубан В. А., Помыткин В. В. Интеграционная модель бизнеса в сфере воздушного транспорта в рамках проводимой государственной политики // Вестник Бурятского государственного университета. Экономика и менеджмент. 2019. Вып. 1. С. 33-39.

В «Транспортной стратегии Российской Федерации до 2030 года», утвержденной Министерством транспорта Российской Федерации, раскрываются перспективы развития воздушного транспорта, связанные с консолидацией бизнеса, структурированием, повышением эффективности и финансовой стабильности авиакомпаний, в том числе при активной поддержке государства ${ }^{1}$.

\footnotetext{
${ }^{1}$ О внесении изменений в Транспортную стратегию РФ: распоряжение Правительства РФ от 11.06.2014 № 1032-р, утв. распоряжением Правительства РФ от 22.11.2008 № 1734-p
} 
Воздушный транспорт обладает мощной инфраструктурой, и для России, которая является огромной континентальной страной, характеризующейся суровыми климатическими условиями, значение воздушного транспорта особенно велико [1].

Рыночные преобразования в стране принесли в сферу воздушного транспорта наряду с положительными негативные последствия. Вместо одного «Аэрофлота» спонтанно сформировалось более трехсот небольших авиакомпаний. Резкое повышение цен на топливо, рост эксплуатационных расходов самолетов и задержка в производстве новых отечественных самолетов сопровождались постоянным увеличением тарифов, в связи с чем был потерян массовый внутренний пассажир [6].

При этом изменения в организационных структурах в воздушном транспорте спровоцировали проблематичные вопросы взаимодействия с государственными органами в распределении полномочий между ними и предприятиями авиационной сферы [2]. Все это способствовало дестабилизации в организационных механизмах, приводящих к возникновению недобросовестной конкуренции, а это отрицательно повлияло на возможность авиакомпаний, аэропортов и правительственных учреждений активно влиять на состояние рынка воздушных перевозок и рост объемов перевозок [8].

В данной связи ключевыми направлениями повышения эффективности как самого сектора воздушного транспорта, так и реализуемой государственной политики в данной сфере являются [3; 4; 5]:

1. Необходимость увеличения транзитных потоков межстрановых грузовых и пассажирских авиаперевозчиков иностранных авиакомпаний на транссибирских, кросс-полярных, трансвосточных, трансазиатских и других международных воздушных коридорах.

2. Интенсивное развитие грузовых воздушных перевозок Российской Федерации и их интеграция в глобальную транспортную систему.

3. Поступательное развитие местных и региональных авиаперевозок в России.

4. Обеспечение сбалансированности спроса и предложения услуг воздушного транспорта, соответствия между потребностями и возможностями.

В этом отношении воздушный транспорт России обеспечивает создание условий для интенсивного экономического роста в России и улучшения качества жизни граждан.

Задача улучшения организации перевозок является одним из приоритетов для всех авиакомпаний, а ключевым фактором становится увеличение эффективности скорости, в том числе в связи с сокращением издержек. Сегодня можно утверждать, что многие проблемы и задачи организационного и экономического развития воздушного транспорта, управления авиаперевозчиками, аэропортами и другими авиакомпаниями с учетом новых тенденций в развитии глобального воздушного транспорта, остаются нерешенными.

Интересным представляется мнение Б. Г. Хаирова, утверждающего, что в условиях конкуренции, в процессе взаимодействия бизнес-структур и органов государственной власти, материальные потоки и различные формы сотрудничества формируются в единую логистическую сеть. При этом для достижения синергетических эффектов в сотрудничестве с бизнесом и правительством необходимо использовать форму многостороннего партнерства, что возможно, если принцип паритета используется в рамках единой системы логистики [10]. 
B. А. Рубан, В. В. Помыткин. Интеграционная модель бизнеса в сфере воздушного транспорта в рамках проводимой государственной политики

Мы считаем, что построение модели интеграции бизнес-структур воздушного транспорта в рамках проводимой государственной политики позволит решить многие проблемы и обеспечить результативность деятельности авиакомпаний. Это обусловлено тем, что интеграция участников взаимодействия в сфере воздушного транспорта на базе научно обоснованных принципов позволит получать все выгоды от долгосрочного сотрудничества, гибко и быстро решить все возникающие проблемы и нести совместную ответственность в повышении качества и доступности транспортных услуг.

Высокая степень эластичности колебаний экономической ситуации допускает разработку адекватной модели сотрудничества бизнеса и государства, которая позволяет корпоративным структурам и государственным органам адаптироваться к изменениям внешней среды [10]. На рисунке 1 представлена разработанная нами интеграционная модель бизнеса в сфере воздушного транспорта в рамках проводимой государственной политики.

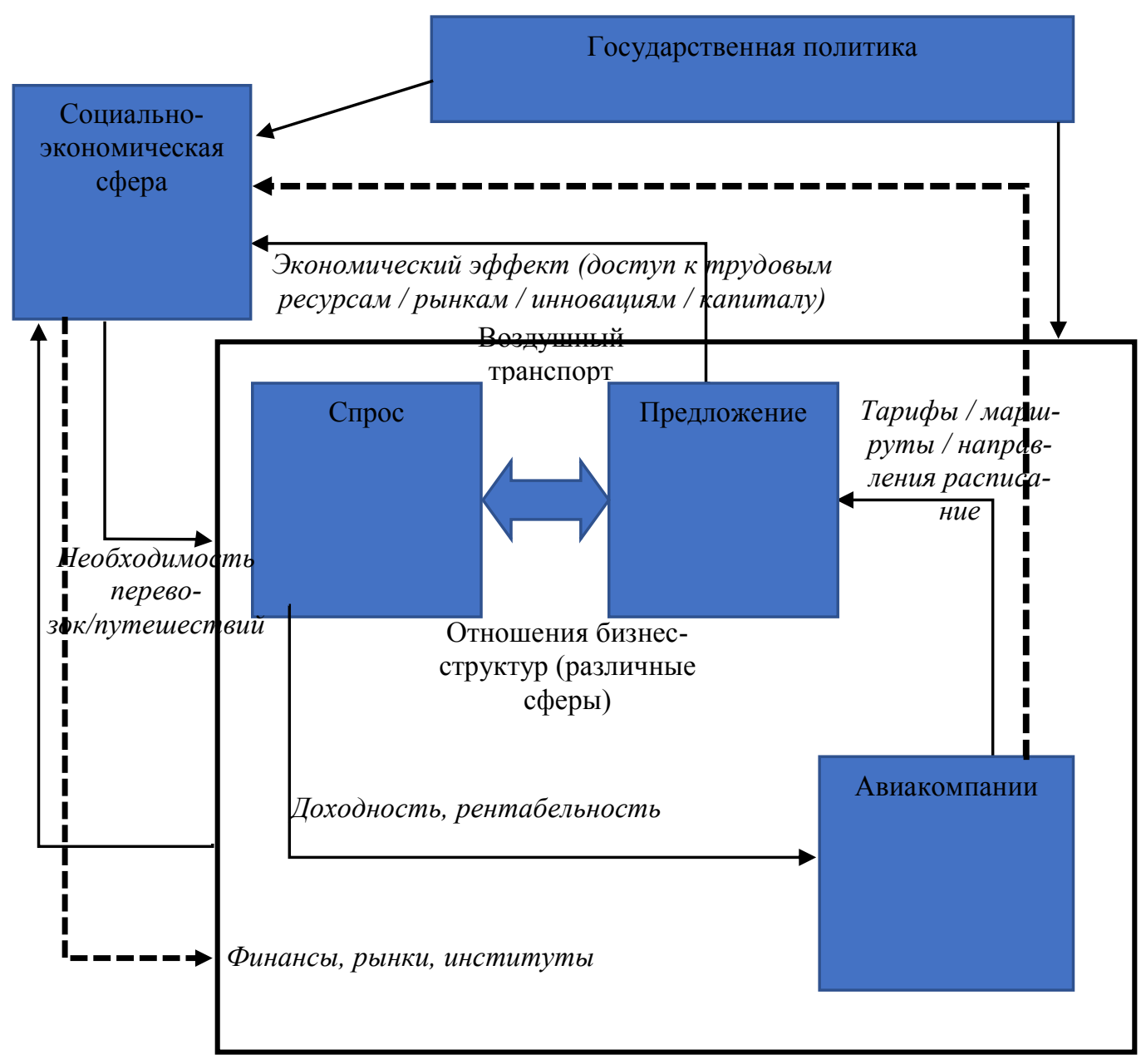

Рис. 1. Модель интеграции бизнеса в сфере воздушного транспорта (разработана авторами) 
Модель демонстрирует внешние и внутренние взаимосвязи между социальноэкономической сферой и системой воздушного транспорта. Связь между социально-экономической сферой, спросом на воздушные перевозки и предложением авиакомпаний, а также возникновение эффектов от этого взаимодействия происходят в рамках предложенной модели, что позволяет учитывать интересы всех субъектов, участвующих в процессах. Выявленные взаимосвязи дают возможность детализировать и сформировать структуру модели интеграции бизнеса в сфере воздушного транспорта, которая представлена на рисунке 2.

Информационное взаимодействие предприятий воздушного транспорта.

Система транспортного обслуживания на основе информационно-экономической интеграции воздушного транспорта и хозяйствующих субъектов.

Формирование единого информационного пространства взаимодействия.

Анализ современного состояния воздушного транспорта для выявления существующих ограничений и преимуществ ее дальнейшего развития.

Анализ пространственной структуры грузопотребления и грузообразования всех хозяйствующих субъектов, региональных, межрегиональных и межстрановых товарообменов. Определение перспектив и процессов интеграции всех субъектов воздушного транспорта на основе информационных технологий.

Развитие межрегиональных и региональных транспортных взаимосвязей посредством разработки концептуальных схем взаимодействия.

Формирование информационно поля реализации информационно-экономических взаимосвязей

\begin{tabular}{|c|c|c|}
\hline \multicolumn{3}{|c|}{ Интеграция предприятий воздушного транспорта } \\
\hline $\begin{array}{l}\text { Блок 1. Разработка ос- } \\
\text { новных положений }\end{array}$ & $\begin{array}{c}\text { Блок 2. Разработка методи- } \\
\text { ческого инструментария }\end{array}$ & $\begin{array}{l}\text { Блок 3. Разработка меха- } \\
\text { низма реализации }\end{array}$ \\
\hline 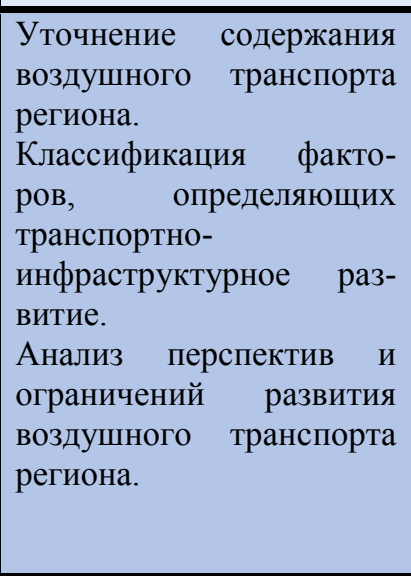 & $\begin{array}{l}\text { Концептуальные схемы орга- } \\
\text { низационного взаимодействия } \\
\text { воздушного транспорта и хо- } \\
\text { зяйствующих субъектов. } \\
\text { Система показателей оценки } \\
\text { информационно- } \\
\text { экономической интеграции } \\
\text { воздушного транспорта и хо- } \\
\text { зяйствующих субъектов. } \\
\text { Методика оценки эффектив- } \\
\text { ности влияния информацион- } \\
\text { но-экономической интеграции } \\
\text { на развитие воздушного } \\
\text { транспорта региона }\end{array}$ & $\begin{array}{l}\text { Технология реализации } \\
\text { интеграции бизнеса в еди- } \\
\text { ной системе информацион- } \\
\text { ного обеспечения. } \\
\text { Преобразование и транс- } \\
\text { формация информационно- } \\
\text { го взаимодействия на еди- } \\
\text { ном экономическом про- } \\
\text { странстве. } \\
\text { Унификация систем управ- } \\
\text { ления информационным } \\
\text { взаимодействием предпри- } \\
\text { ятий воздушного транспор- } \\
\text { та }\end{array}$ \\
\hline
\end{tabular}

Рис. 2. Структура модели интеграции бизнеса в сфере воздушного транспорта 
B. А. Рубан, В. В. Помыткин. Интеграционная модель бизнеса в сфере воздушного транспорта в рамках проводимой государственной политики

Структура модели интеграции бизнеса в сфере воздушного транспорта может служить основой для дальнейших действий органов государственной власти в направлении совершенствования процессов взаимодействия и корректировки государственной политики для усиления позитивного влияния воздушного транспорта на социально-экономическую сферу. В рамках предложенной модели может осуществляться взаимодействие бизнес-структур, при этом следует понимать, что государственное регулирование сферы воздушного транспорта также нуждается в некоторой степени интеграции, позволяющей всем уровням государственного и муниципального управления координировать и направлять общие усилия на развитие воздушного транспорта и усиливать его воздействие на социально-экономическую систему территории региона и страны.

Нами установлено, что развитие воздушного транспорта в условиях интеграционных процессов определяется различными организационными формами взаимодействия с пространственной, экономической и информационной точки зрения, посредством построения моделей транспортного обслуживания и перемещения в пространстве материальных потоков (пассажиров, грузов) в сфере товарообмена на основе совместного использования системы информационного обеспечения. Рационализация моделей транспортного обслуживания определяется количественными и качественными показателями развития: общим объемом грузоперевозок, направлением и длиной маршрута, спросом со стороны потребителей, системой тарифов и цен на услуги и др.

Таким образом, мы считаем, что миссия государственной политики в сфере воздушного транспорта заключается в предоставлении интегрированной, доступной, безопасной, надежной, устойчивой и качественной транспортной системы и инфраструктуры посредством социально справедливых и экономически эффективных процессов развития и расширения прав и возможностей субъектов взаимодействия транспортного процесса, поэтому в качестве целей интеграции бизнеса в сфере воздушного транспорта мы предлагаем определить:

- $\quad$ необходимость использования транспортной политики в качестве стратегических инструментов для достижения роста, развития, реконструкции и перераспределения ресурсов;

- $\quad$ интеграцию транспортной политики с другими секторальными сферами национальной экономики на основе программно-целевого подхода с учетом интересов всех субъектов взаимодействия;

- сокращение существующего неравенства в доступе к возможностям за счет использования инструментов политики в области транспорта и пространственного развития;

- обеспечение создания необходимых механизмов для адекватной координации между различными бизнес-структурами.

Применение предложенных мероприятий в практической деятельности на основе предлагаемых нами структуры и модели интеграции бизнеса в сфере воздушного транспорта в рамках проводимой государственной политики позволит повысить качество и доступность авиатранспортных услуг за счет сбалансированности взаимодействия всех предприятий, участвующих в процессах авиаперевозки. 


\section{Литература}

1. Андреев А. В. Методологические основы исследования этапов развития отрасли воздушного транспорта и глобализации авиатранспортного рынка // ТДР. 2012. № 6(1). С. 253-256.

2. Войтенко В. П. Особенности взаимодействия государства и воздушного транспорта России при использовании механизма государственно-частного партнерства // Скиф. 2016. №5. С. 37-41.

3. Вороницына Г. С., Ребезова М. И. Перспективы развития систем взаиморасчетов на воздушном транспорте как каналов дистрибуции услуг воздушного транспорта, в конкуренции с web-сайтами авиакомпаний // Научный вестник МГТУ ГА. 2015. № 214(4). C. $37-44$.

4. Горбачова О. Н. Модель рациональных ожиданий и возможности ее использования в управлении современными аэропортами // Актуальные проблемы экономики и права. 2013. №3 (27). С.63-70.

5. Губенко В. А. Методы кластеризации и классификации аэропортовых предприятий в оценке стратегических позиций на рынке авиатранспортной сферы // ТДР. 2016. № 2. С. 173-177.

6. Иванов И. А. Анализ направлений совершенствования экономического развития и отраслевой организации перевозок на воздушном транспорте // Научный вестник МГТУ ГА. 2015. № 214 (4). С. 53-56.

7. Иванов И. А., Богатырев А. А. О направлениях развития системы перевозок на воздушном транспорте // Научный вестник МГТУ ГА. 2014. № 202. С.25-27.

8. Титов Б. А., Кропивенцева С. А. Модель экономического взаимодействия авиаперевозчика и аэропортовых структур // Вестник СГАУ. 2013. № 2(40). С.235-242.

9. Хаиров Б. Г. Потоки взаимодействия власти и бизнеса // Российское предпринимательство. 2013. № 7(229). С. 18-24.

10. Хегай Ю. А., Лукьяненко Е. С. Проблемы интеграции в мировое транспортное пространство и реализации транзитного потенциала страны // Теория и практика общественного развития. 2015. № 21. С. 69-72.

11. Рубан В. А., Метелева М. А. Механизмы управления государственно-частным партнерством в инвестиционной политике формирования инфраструктуры региона: пути оптимизации и развития // Вестник ВСГУТУ. 2017. № 1(64). С. 117-124.

\section{INTEGRATION MODEL OF BUSINESS IN THE FIELD \\ OF AIR TRANSPORT WITHIN THE FRAMEWORK OF THE CURRENT STATE POLICY}

Vladimir A. Ruban

Dr. Sci. (Econ.), Prof. of State and Municipal Administration Department,

Siberian State Transport University

191 Dusi Kovalchuk St., Novosibirsk 630049, Russia

E-mail: gmu@sgups.stu.ru

Vladimir V. Pomytkin

Research Assistant,

Siberian State Transport University

191 Dusi Kovalchuk St., Novosibirsk 630049, Russia

E-mail: gmu@sgups.stu.ru

A study of the practical aspects of air transport functioning in Russia and the current state policy in this field has shown the need to improve the considered processes. The article sub- 
B. А. Рубан, В. В. Помыткин. Интеграционная модель бизнеса в сфере воздушного транспорта в рамках проводимой государственной политики

stantiates that one of the perspectives for improving state regulation of economic activities is the integration of air transport and business structures in intraregional, interregional and inter-country air transportation. Given this we propose an integration model for business in the field of air transport within the framework of current state policy. The proposed model reflects the correlation of the economy, demand for air transportation and supply of airlines, and allows taking into account the interests of all subjects of interaction. We have developed a methodical approach to formulation of the strategic directions for the development of air transport aimed at building a transport service system, based on the economic integration of business in the field of air transport.

Keywords: economic integration; state regulation; air transportation; air transport. 